DOI: 10.12731/2227-930X-2018-4-55-65 УДК 691.115

\title{
ПОЛУЧЕНИЕ СТРОИТЕЛЬНОГО ТЕПЛОИЗОЛЯЦИОННОГО МАТЕРИАЛА ИЗ ОТХОДОВ ДЕРЕВООБРАБОТКИ
}

\author{
Гудков Д.Н., Дубровская О.Г., Кулагин В.А.
}

Современные тенденщии предполагают использование отходов производства, что делает работу предприятия более экологически чистьм. Одним из направлений является использование отходов деревообрабатывающей промышленности для получения строительньхх изделий и материалов. Перед получением необходимого строительного материала древесные опилки подвергают предварительной обработке - для улучшения технических характеристик будущего изделия. В статье рассматривается метод получения утеплителя из древесных опилок, обработанных в кавитационной установке, $и$ в последующем спрессованных. Приведень сравнительныле характеристики теплоизоляционных свойств с аналогали, выявлены преимущчества и недостатки. Использование опилок в качестве сырья для производства экологически чистых теплоизоляциионных строительных материалов позволяет создавать замкнутые цикльы производства, и как следствие значительно снизить негативное влияние предприятий деревообработки на окружаюшую среду. В качестве выводов предлагается использование гидродинамической обработки как метода по улучшению технических характеристик изделия без значительного повышения стоимости материала.

Цель - описание метода получения строчтельного теплоизоляционного материала, на основе гидротермодинамического кавитационного воздействия.

Материалы и метод работы: в работе использованы опилки хвойных пород деревьев, методы гидротермодинамической обработки, аналитические методь определения теплоизоляичинных свойств. 
Результаты: получен строительный теплоизоляционный материал в виде деревянных брикетов, имеющих меньшую плотность и ряд конкурентных преимуществ в сравнении с аналогами.

Область применения результатов: полученный результат рачионально применять в строительной сфере, где необходим экологически чистый теплоизоляционный материал с высокими показателями теплосбережения.

Ключевые слова: очистка сточных вод; строчтельный материал; кавитация

\section{RECEIVING BUILDING HEAT-INSULATING MATERIAL FROM WOODWORKING WASTES}

\section{Gudkov D.N., Dubrovskaya O.G., Kulagin V.A.}

Current trends involve the use of waste, what makes the enterprise more environmentally friendly. One of the direction is using woodworking wastes for receiving building materials. Before obtaining the necessary building material sawdust is subjected to pretreatment - to improve the technical characteristics of the future product. This article describes the method of obtaining insulation material from sawdust with special pretreatment: processing in cavitator and then pressing. Comparative characteristics of heat-insulating properties with analogues are given, advantages and disadvantages are revealed. Using sawdust as raw material for production ecological heat-insulating building materials allows to create closed production cycle. Besides this method can significantly decrease negative influence of woodwork production on the environment. As conclusions, it is proposed to use hydrodynamic processing as a method to improve the technical characteristics of the product without significantly increasing the cost of the material.

Keywords: wastewater treatment; building material; cavitation technology. 


\section{Введение}

Сегодня большое внимание уделяется вопросу экологизации производства. Производственные процессы предприятий предполагают наличие различного рода отходов, задачи утилизации которых необходимо решать в свете разработки и применения энергоресурсосберегающих и экологически целесообразных технологий. Разработано множество технических решений, которые предлагают использовать отходы производства для создания материалов с улучшенными характеристиками. Например, создание теплоэффективной бетонной смеси на основе отходов производства утеплителя пеноплекс [1, с. 61-63], использование остатков производства деревообработки и гофрокартона [2, с. 26-35], бетона [3, с. 217-221] или создание теплоизоляционного материала на основе термореактивных смол и отходов теплоэнергетики [4, с. 48-52]. В данной статье рассматривается использование древесных опилок хвойных пород деревьев как отхода деревообрабатывающего производства.

\section{Методы, используемые в работе}

В отличие от прямого способа получения деревянной плиты [5, с. 248-250], было предложено осуществить предварительную обработку опилок в кавитационной установке. Установлено, что сила аутогезионного взаимодействия между древесными частицами зависит от содержания поверхностных реакционо способных активных групп [6, с. 159-163; 7, с. 60-62; 8, с. 182-185] и плотности получаемого материала. Поэтому предлагается с целью повышения активности древесины гидродинамическая обработка. Для этого было взята водная эмульсия 6\%-го водного раствора древесных опилок, обработанных в кавитационной установке с лопастным реактором, при режиме 3000 об/мин. в течение 10 минут. Далее осуществлялось горячее прессование обработанных опилок при температуре 190 градусов Цельсия и удельном давлении 1,9 МПа. Удельная продолжительность прессования принята 1,5 мин/мм. Показатели касающиеся характеристик теплоизоляцион- 
ных свойств полученного строительного материала были оценены стандартными методиками испытаний.

\section{Результаты}

Итоговые технические характеристики, полученного теплоизоляционного материала после проведения всех операций, указаны в таблице 1.

Таблицุа 1.

Технические характеристики деревянных плит

\begin{tabular}{|c|c|c|c|}
\hline Характеристика & Метод испытаний & $\begin{array}{c}\text { Величина } \\
\text { измерения }\end{array}$ & Результат \\
\hline Прочность на сжатие & ГОСТ EN 826-2011 & МПа & $2,27 *$ \\
\hline $\begin{array}{c}\text { Водопоглощение } \\
\text { за } 24 \text { часа }\end{array}$ & \multirow{2}{*}{ ГОСТ 15588-86 } & \multirow{2}{*}{ \% по объему } & 0,3 \\
\hline $\begin{array}{c}\text { Водопоглощение } \\
\text { за } 28 \text { суток } \\
\end{array}$ & & & 0,5 \\
\hline $\begin{array}{c}\text { Категория стойкости к } \\
\text { огню, группа горючести }\end{array}$ & Ф3-123 & группа & $\Gamma 4$ \\
\hline $\begin{array}{c}\text { Коэффициент } \\
\text { теплопроводности }\end{array}$ & СП 50.13330.2012 & $(\mathrm{BT} / \mathrm{M}) \cdot{ }^{\circ} \mathrm{K}$ & $0,0325^{*}$ \\
\hline $\begin{array}{c}\text { Звукоизоляция } \\
\text { перегородки }\end{array}$ & ГОСТ 27296-87 & дБ & 41 \\
\hline Плотность & ГОСТ 21523.11-79 & кг / & от 220 \\
\hline Модуль упругости & ГОСТ 21523.8-87 & МПа & 15 \\
\hline Удельная теплоемкость & ГОСТ 21523.3-87 & кДж / (кг $\left.\cdot{ }^{\circ} \mathrm{C}\right)$ & 1,45 \\
\hline $\begin{array}{l}\text { Предел прочности при } \\
\text { статическом изгибе }\end{array}$ & ГОСТ 21523.1-93 & МПа & $0,48^{*}$ \\
\hline $\begin{array}{c}\text { Температурный диапазон } \\
\text { эксплуатации }\end{array}$ & ТУ & ${ }^{\circ} \mathrm{C}$ & $-70 \ldots+75$ \\
\hline
\end{tabular}

* - указаны средние значения

\section{Обсуждение полученных результатов}

Чтобы определить преимущества и недостатки, проведено сравнение ряда характеристик с аналогичными изделиями, которые также получены из отходов производства деревообработки. Для сравнения взяты как аналоги конструкционно-отделочных материалов: 
- древесноволокнистая плита ДВП (аналог 1);

- древесностружечная плита ДСП (аналог 2).

так и теплоизоляционных материалов:

- задувная древесная вата;

- маты и плиты из древесного утеплителя.

На рисунке 1 приведены результаты сравнения следующих характеристик:

- водопоглощение за 24 часа;

- предел прочности при статическом изгибе;

- теплопроводность.

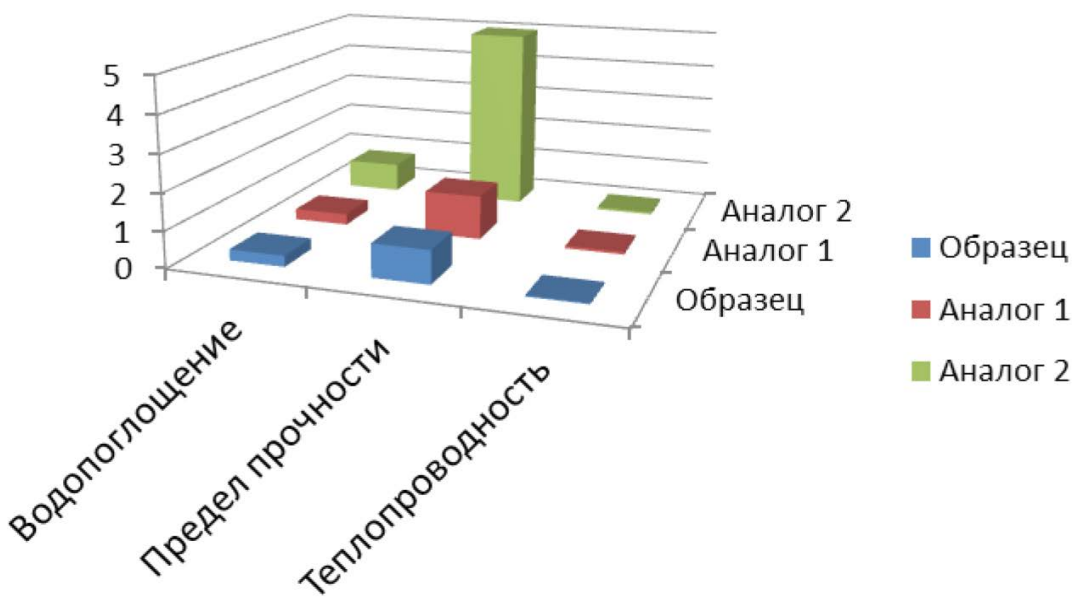

Рис. 1. Сравнение характеристик образца с аналогами

При возможном сравнении физико-механических свойств полученных плит с требованиями ГОСТ 4598-86. «Плиты древесноволокнистые. Технические условия» можно отнести данный материал к марке плит М2 (мягкие), но по показателю прочности и показателю разбухания по толщине - к марке Т (твердые).

Это обуславливается тем, что гидродинамическая диспергация позволяет получить повышенное содержание активных функциональных групп на поверхности опилок и тем самым обеспечить требуемое количество связей между ними при сравнительно малой 
плотности материала. Нужно отметить, что физико-механические свойства плитных материалов существенно зависят от фракционного состава исходной древесной массы.

При исследовании каитационных процессов, осуществляется изомеризация и окисление лигнина с образованием лигносульфонатов, являющихся технически полученной формой лигнина и обладающих важным свойством вяжущего составляющего - «клея». Стоит отметить, что в количественном отношении при кавитационной обработке лигносульфанатов выделяется на 50\% больше, чем при 3-часовой выдержке опилок в водной среде. Это означает, что обработка в гидродинамическом диспергаторе повышает параметр связности у получаемых в дальнейшем плит из данной суспензии, делая связи между частицами прочнее и, следовательно, надежнее сам строительный материал.

Согласно рисунку 1, полученный материал не уступает аналогичным по водопоглощению, что обеспечивается предварительной обработкой опилок. Сравнение по пределу прочности при статическом изгибе показывает, что разрабатываемый материал является более хрупким при эксплуатации, что объясняется меньшим показателем плотности. С другой стороны, это обеспечивает облегчение конструкции и уменьшение веса при транспортировке. Как видно из диаграммы, коэффициент теплопроводности у приведенного образца ниже, чем у аналогичных изделий, соответственно материал будет лучше сохранять тепло внутри здания. Еще одним важным преимуществом данного материала является гидрофобность теплоизоляционного материала без присутствия дополнительных веществ, применяемых в аналогах. Так стандартная технология производства матов и плит древесного утеплителя предполагает добавление к волокнам воды, латекса, придающего изделию прочность, и парафина, предназначенного для гидрофобизации изолятора. Теплоизоляционная плита из кавитационно-модифицированной опилочной суспензии обладает собственной гидрофобностью.

Из недостатков стоит выделить низкую устойчивость к возгоранию (класс Г4), низкая степень прочности [9, с. 1290; 10, с. 1602]. Исключить указанные недостатки можно используя определённые 
защитные пропитки для строительных материалов [11, с. 313; 12, с. 70], а также усиление конструкции металлическими элементами $[13$, c. $479 ; 14$, с. $192 ; 15$, c. 123$]$.

\section{Выводы}

Древесина является возобновляемым, повторно используемым и экологически чистым продуктом. В качестве строительного теплоизоляционного материала предлагаемые кавитационно-модифицированные древесные плиты конкурентоспособны за счет высоких технико-эксплуатационных показателей и возможности варьирования свойств и усиления ряда характеристик на стадии производства. Также немаловажно, что применение данной технологии позволяет решать задачи утилизации отходов деревообрабатывающих предприятий и как следствие ведет к улучшению экологической ситуации региона.

\section{Список литературы}

1. Шарапов О.Н. Теплоэффективные бетонные смеси с применением отходов отпроизводства пеноплэкса // Университетская наука, 2017, №2. С. 61-63.

2. Лукаш А.А. Эффективные строительные материалы и изделия из техногенных отходов для жилищного строительства // Вестник ПГТУ, 2017, №2. С. 26-35.

3. Бацанова С.В., Ковалевская К.Ю., Кафтаева А.Н., Шугаева М.А., Марушко М.В. Разработка и исследование свойств энергосберегающего экологически чистого штукатурного покрытия для внутренних стен зданий на основе отходов производств газобетонов // Экономика. Общество. Человек: Межвузовский сборник научных трудов, 2013 С. 217-221.

4. Зелинская Е.В. Теплоизоляционный материал на основе термореактивных смол и отходов теплоэнергетики. // Строительные материалы, 2015. С. 48-52.

5. Журавлева Л.Н. Производство мягких древесноволокнистых плит - одно из направлений переработки отходов // Актуальные проблемы лесного комплекса, 2009, №22. С. 248-250. 
6. Баяндин М.А. Влияние механоактивации на аутогезионные свойства древесины // Хвойные бореальной зоны, 2013, №1. С. 159-163.

7. Гудков Д.Н. Получение теплоизоляционного материала из отходов деревообработки, модифицированных гидротермодинамическим воздействием // Проспект Свободный-2017: материалы международной науч. конф., посвященной году экологии в России, 2017. С. 60-62.

8. Баяндин М.А. Влияние мелкодисперсных фракций на формирование свойств древесных плит без связующего // Хвойные бореальной зоны, 2015, №3. С. 182-185.

9. Jiří Zacha, Jitka Hroudováb, Jiří Brožovskýc, Zdeněk Krejzad, Albinas Gailiuse. Development of Thermal Insulating Materials on Natural Base for Thermal Insulation Systems // Procedia Engineering, 2013, no. 57, pp. 1288-1294.

10. Martin Volf. Thermal, moisture and biological behaviour of natural insulating materials // Energy Procedia, 2017, no. 78, pp. 1599-1604.

11. F. Asdrubali. A review of structural, thermo-physical, acoustical, and environmentalproperties of wooden materials for building applications // Building and Environment, 2017, no. 114, pp. 307-322.

12. Martin Nemecek. Influence of thermal storage mass on summer thermal stability in a passive wooden house in the Czech Republic // Energy and Buildings, 2015, no. 107, pp. 68-75.

13. Bozena Orlik-Kozdon. Assessment of the application efficiency of recyclingmaterials in thermal insulations // Construction and Building Materials, 2017, no. 156, pp. 476-485.

14. Davor Krzisnik. Micro and material climate monitoring in wooden buildings in sub-Alpine environments // Construction and Building Materials, 2018, no. 166, pp. 188-195.

15. Леонович О.К. Повышение долговечности и экологической безопасности стеновых панелей деревянных домов каркасного типа // Труды БГТУ. Лесная и деревообрабатывающая промышленность, 2014, №2. С. 122-124.

\section{References}

1. Sharapov O.N. Teploeffektivnye betonnye smesi s primeneniem otkhodov ot proizvodstva penopleksa [Heat-efficient concrete mixes with 
the use of waste foam production]. Universitetskaya nauka [University science], 2017, no. 2, pp. 61-63.

2. Lukash A.A. Effektivnye stroitelnye materialy i izdeliya iz tekhnogennykh otkhodov dlya zhilishchnogo stroitelstva [Efficient building materials from technological wastes for housing]. Vestnik PGTU [Herald PGTU], 2017, no. 2, pp. 26-35.

3. Batsanova S.V., Kovalevskaya K.Yu., Kaftaeva A.N., Shugaeva M.A., Marushko M.V. Razrabotka i issledovanie svoystv energosberegayushchego ekologicheski chistogo shtukaturnogo pokrytiya dlya vnutrennikh sten zdaniy na osnove otkhodov proizvodstv gazobetonov [Development and research of the properties of energy-saving environmentally friendly plaster coating for the interior walls of buildings based on waste production of aerated concrete]. Ekonomika. Obshchestvo. Chelovek: Mezhvuzovskiy sbornik nauchnykh trudov [Economic. Society. Person: Interuniversity collection of scientific papers], 2013, pp. 217-221.

4. Zelinskaya E.V. Teploizolyatsionnyy material na osnove termoreaktivnykh smol i otkhodov teploenergetiki [Heat-insulation material based on thermosetting resins and waste heat-and-power engineering]. Nauchno-tekhnicheskiy i proizvodstvennyy zhurnal «Stroitelnye materialy» [Scientific and technical journal «Building materials»], 2015, pp. 48-52.

5. Zhuravleva L.N. Proizvodstvo myagkikh drevesnovoloknistykh plit [The production of soft fibreboard]. Aktualnye problemy lesnogo kompleksa [Actual problems of forestry], 2009, no. 22, pp. 248-250.

6. Bayandin M.A. Vliyanie mekhanoaktivatsii na autogezionnye svoystva drevesiny [Effect of mechanical activation on autogenic properties of wood]. Khvoynye borealnoy zony [Conifers of the boreal zone], 2013, no. 1, pp. 159-163.

7. Gudkov D.N. Poluchenie teploizolyatsionnogo materiala iz otkhodov derevoobrabotki, modifitsirovannykh gidrotermodinamicheskim vozdeystviem [Production of heat-insulating material from woodworking waste modified by hydrothermodynamic effects]. Prospekt Svobodnyy-2017: materialy mezhdunarodnoy nauchnoy konferentsii [Prospekt Svobodnyy-2017: international scientific conference materials], 2017, pp. 60-62. 
8. Bayandin M.A. Vliyanie melkodispersnykh fraktsiy na formirovanie svoystv drevesnykh plit bez svyazuyushchego [The effect of fine fractions on the formation properties of wood-based panels without a binder]. Khvoynye borealnoy zony [Conifers of the boreal zone], 2015, no. 3 , pp. 182-185.

9. Jiří Zacha, Jitka Hroudováb, Jiř́i Brožovskýc, Zdeněk Krejzad, Albinas Gailiuse. Development of Thermal Insulating Materials on Natural Base for Thermal Insulation Systems. Procedia Engineering, 2013, no. 57, pp. 1288-1294.

10. Martin Volf. Thermal, moisture and biological behaviour of natural insulating materials. Energy Procedia, 2017, no. 78, pp. 1599-1604.

11. F. Asdrubali. A review of structural, thermo-physical, acoustical, and environmentalproperties of wooden materials for building applications. Building and Environment, 2017, no. 114, pp. 307-322.

12. Martin Nemecek. Influence of thermal storage mass on summer thermal stability in a passive wooden house in the Czech Republic. Energy and Buildings, 2015, no. 107, pp. 68-75.

13. Bozena Orlik-Kozdon. Assessment of the application efficiency of recyclingmaterials in thermal insulations. Construction and Building Materials, 2017, no. 156, pp. 476-485.

14. Davor Krzisnik. Micro and material climate monitoring in wooden buildings in sub-Alpine environments. Construction and Building Materials, 2018, no. 166, pp. 188-195.

15. Leonovich O.K. Povyshenie dolgovechnosti i ekologicheskoy bezopasnosti stenovykh paneley derevyannykh domov karkasnogo tipa [Increase of durability and environmental safety of wall panels of wooden houses of frame type]. Trudy BGTU: Lesnaya i derevoobrabatyvayushchaya promyshlennost' [BGTU materials: timber and woodworking industry], 2014, no. 2, pp. 122-124.

\section{ДАННЫЕ ОБ АВТОРАХ}

Гудков Дмитрий Николаевич, аспирант 3-го курса обучения Сибирский федеральный университет

пр. Свободный, 79, Красноярск, 660041, Российская Федераџия dione-nomad@mail.ru 
Кулагин Владимир Алексеевич, заведующий кафедрой Теплотезники и гидрогазодинамики, доктор технических наук, профессор

Сибирский федеральный университет

пр. Свободный, 79, Красноярск, 660041, Российская Федерачия

VKulagin@sfu-kras.ru

Дубровская Ольга Геннадьевна, заместитель директора по учебно-методической работе, кандидат технических наук, доцент

Сибирский федеральныгй университет

пр. Свободный, 79, Красноярск, 660041, Российская Федераиия

Odubrovskaya@sfu-kras.ru

\section{DATA ABOUT THE AUTHORS}

Gudkov Dmitriy Nikolaevich, third-year Post-Graduate Student

Siberian Federal University

79, Svobodny ave., Krasnoyarsk, 660041, Russian Federation dione-nomad@mail.ru

Kulagin Vladimir Alekseevich, Head of the Department of Thermal Engineering and Fluid Dynamics, Doctor of Technical Sciences, Professor

Siberian Federal University

79, Svobodny ave., Krasnoyarsk, 660041, Russian Federation VKulagin@sfu-kras.ru

Dubrovskaya Olga Gennadevna, Deputy Director for Study, Candidate of Technical Sciences, Docent Siberian Federal University 79, Svobodny ave., Krasnoyarsk, 660041, Russian Federation Odubrovskaya@sfu-kras.ru 